\title{
Animals Make Music: A Look at Non-Human Musical Expression
}

\author{
Reinhard Gupfinger * and Martin Kaltenbrunner
}

Institute of Media Studies, University of Art and Design Linz, 4020 Linz, Austria; martin.kaltenbrunner@ufg.at

* Correspondence: reinhard.gupfinger@ufg.at

Received: 20 April 2018; Accepted: 28 August 2018; Published: 2 September 2018

\begin{abstract}
The use of musical instruments and interfaces that involve animals in the interaction process is an emerging, yet not widespread practice. The projects that have been implemented in this unusual field are raising questions concerning ethical principles, animal-centered design processes, and the possible benefits and risks for the animals involved. Animal-Computer Interaction is a novel field of research that offers a framework (ACI manifesto) for implementing interactive technology for animals. Based on this framework, we have examined several projects focusing on the interplay between animals and music technology in order to arrive at a better understanding of animal-based musical projects. Building on this, we will discuss how the implementation of new musical instruments and interfaces could provide new opportunities for improving the quality of life for grey parrots living in captivity.
\end{abstract}

Keywords: ACI; animal music; animal-centered design; metamusic

\section{Introduction}

The number of physical products and software applications developed specifically for animals and the commercial interest in technological mediators for human-animal interactions is growing [1-4]. In addition to the physical and graphical interaction design aspects of such technology, sound and music can also play an important role in the design process [5]. Despite the increasing amount of hardware and software for animals, there are only a few studies devoted to the use of audio technologies to enrich the living environment of animals in captivity [6-8].

In 2016, a research project was started by the authors of this paper in collaboration with the artist group alien productions and the zoologists and animal keepers of ARGE Papageienschutz. The principal goal of this project is to design and develop musical instruments and interfaces for a group of grey parrots held in captivity at an animal shelter near Vienna. This research is based on an ongoing art project named metamusic [9], which was initiated in 2012 by alien productions. Adopting an artistic approach, the collective has been investigating how grey parrots react to musical stimuli, exploring whether they can become an intrinsic part of interactive sound installations, and assessing whether they are capable of producing "parrot music" (new music that does not have to sound like music to human ears) by themselves. The project aims to generate artistic output for humans while improving the quality of life for grey parrots in captivity with musical instruments and interfaces.

Recent research in the field of cognitive biology has focused on the role of animals listening to human music as a concept of enrichment [10-13]. Since most of the music is selected by humans, this can lead to anthropomorphic biases. Therefore, the music should be attuned to the animals' auditory skills. Studies have shown that non-human species also have musical skills [14-16] and display entrainment to auditory stimuli $[17,18]$. Animal species such as grey parrots, cockatoos, elephants, primates, pigeons, and carps have been found to be able to discriminate between different 
composers or different genres, prefer music to silence, or move in rhythmic synchronicity to the musical beat $[10,14,17-19]$.

According to further studies, some parrot species such as grey parrots and cockatoos have musical skills and a natural feeling for rhythm [17,18]. Grey parrots, for example, can repeat musical patterns and have the ability to reproduce sounds $[15,20]$. In this respect, it appears appropriate to work with grey parrots in the context of animal-based music.

In 2011, Clara Mancini in her "Animal-Computer Interaction (ACI): A Manifesto" proposed the keystones for ACI as a field of research. ACI research aims to understand the interaction between animals and the computing technology [21], and is therefore a significant step toward an ethical implementation of such technologies. In this manifesto, Mancini discussed ethical principles, guidelines, and methodologies for the design, analysis, and evaluation of ACI systems. To the best of our knowledge, there is no comprehensive summary and analysis of projects that involve animals interacting with music instruments and interfaces. We therefore have examined different approaches and technologies in diverse fields from a musical interface designer's perspective. This paper gives an overview of current technologies and important developments in the context of musical instruments that include animals in the music and sound-generating process, with a focus on the creative and artistic outcomes for both animals and humans. We are interested in gaining a better understanding of the actual role of the animals interacting with such technologies. This paper attempts to determine the factors that could lead to a suitable design approach and its ethical implementation.

\section{Cultural Context}

Musical instruments and interfaces that involve animals as musical agents can be found in different fields such as New Interfaces for Musical Expression (NIME), contemporary art installations, animal cognition experiments, and ACI. Some of the earliest examples of conjectural musical instruments that $(\mathrm{ab})$ use animals as sound generators can be found between the $16^{\text {th }}$ and $19^{\text {th }}$ centuries under the names of the Cat Organ or the Pig Organ ([22], Figure 1). Both are speculative, piano-like instruments in which cats or pigs are placed inside or attached to the instrument. When the keys are pressed, thus poking the pig or pinching the tail of the cat, the animal cries out in pain and generates a pitched sound. Since both instruments are based on inflicting pain upon animals, such bizarre musical instruments have never been built out of ethical and animal welfare concerns. However, these ideas provide evidence of an early interest in humans making music involving animals, in this case, as a structural part of the musical instrument itself. In general, live animals are not usually a constitutive part of musical instruments, and there are not many examples in which such instruments have actually been put into practice.

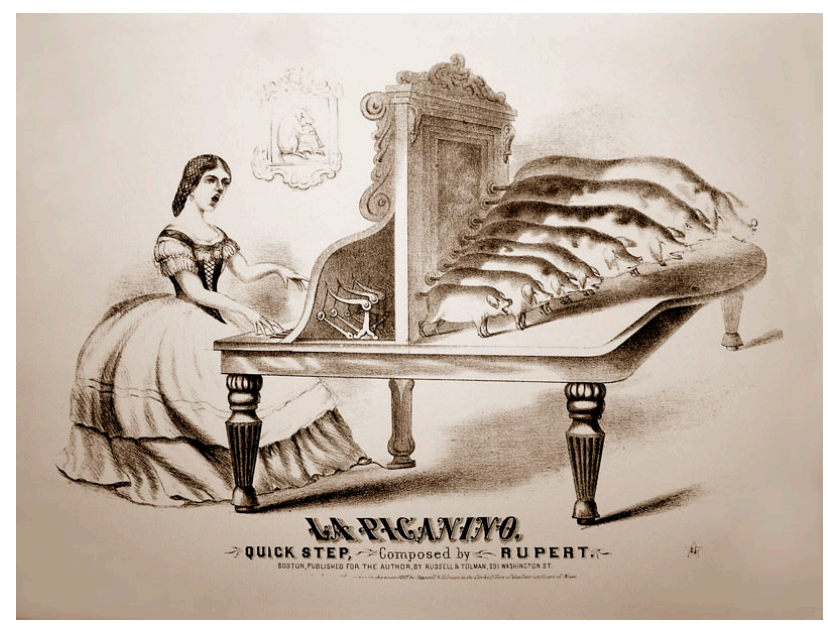

Figure 1. Pig Organ, cover illustration for the piece of sheet music "La Piganino" [22]. 
The idea of animals becoming anthropomorphic musicians playing traditional acoustic instruments is much more common in the literature. Well-known fairy tales such as The Town Musicians of Bremen have popularized this concept. Since the middle of the 20th century, this particular configuration has often been restaged in a circus environment, where, in general, various species including primates were capable of performing various musical tasks through conditioning [23].

A related topic within the field of Human-Computer Interaction (HCI) is the design and use of new technologies for musical expression and artistic performance. Researchers and artists are developing new musical instruments and interfaces with the aim of understanding and influencing new forms of artistic expression, usability, and playability. The introduction and development of new technologies in this field also opens up new possibilities to include animals in the music-generating process. The projects we could find from this community are mostly combinations of a computer vision system tracking the animals, and a sound-generating system, which is controlled by the animals' movements. A common setup in this field is fish-based interfaces [24-30]. The video tracking system observes the fish in the aquarium, and the sounds are generated or processed by the generally random movements of the fish [24]. The output of such fish-based musical interfaces can be manifold and creative, but since the fish are separated from the audio feedback, they lack an animal-centered design approach. Thus, in some of the projects, all of the plants, stones, and other aquarium furniture have been removed to provide a better camera view, which leads to the discussion of potential negative impacts on the living environment of the fish themselves.

Another extensive field in which live animals are used in installations and projects is the contemporary art world. Various projects such as Harness by Robert Wechsler [31] or from here to ear by Céleste Boursier-Mougenot [32] focus on the relationship between animals and humans, and how animals can become the author or co-author of artworks or the creative process. Some artists such as Céleste Boursier-Mougenot deal with the musicality of animals by building installations that involve animals creating sonic environments. Birds, which are known for their musical talents [14,15], often play an important role in such art installations.

In the field of animal cognition, test setups, for example with touchscreens, are sometimes used in experiments to provide an insight into the animals' musicality or musical preferences [1]. However, these test devices are less attractive for musical interface design, because they generally do not focus on a playful design. However, their results, such as evidence of the entrainment of animals to music stimuli $[17,18]$, have great significance for our study. These kinds of test devices have enabled scientists to gather evidence that animal species have auditory skills and musical talents, and examine how these skills work $[15,16]$.

$\mathrm{ACI}$ aims at gaining a better understanding of how animals interact with technology, and thus some ACI employs technology as a mediator between different species, including humans. Even though $\mathrm{ACI}$ is growing fast, the potential opportunities for acoustic enrichment in the context of ACI technology have received little attention.

\section{Musical Animal-Machine Interaction}

Based on the more active or passive role that animals can play in the interaction process with musical instruments and interfaces, we shall now discuss and analyze some projects focusing on the interaction between animals and music technology that we have identified as relevant to ACI. The analysis and classification of these projects provides a source of data that could potentially lead to further contributions in this field, and theoretical improvements in an animal-centered design process. In the following, we shall define four categories, which are generally based on the degree of musical agency of the individual species involved: Animal Movement as Control Source; Animals as Unconscious Performers; Animals as Trained Musicians; and Animals as Voluntary Musicians. Loosely related to the overall evolutionary stage, these categories are based on the musical understanding and the related physical and cognitive abilities of the individual species, which range from a complete lack of any auditory perception and expression to highly developed musical abilities and vocal 
expression. We intend to implement and extend the findings from the last category (Animals as Voluntary Musicians) in our ongoing project to develop and design musical instruments and interfaces for grey parrots.

\subsection{Animal Movement as Control Source}

The first category of musical interfaces generally involves lower life forms such as bacteria or other simple animal species such as worms. These animals either completely lack any auditory sensory capabilities or acoustic expression, or are completely isolated from perceiving any musical stimuli. Thus, in such a configuration, these animals only play a passive role, since they are unable to interact with input devices in the sound generation process, and only serve as nearly aleatory control sources. A typical example of such a musical instrument, which in this case is controlled by live worms, is the Din Datin Dudero project developed by Peter Blasser. As the worms wriggle around metallic contact pins, their movements modify the circuits inside the synth and produce different sounds [33]. The experimental design of the instrument appears to be suited to the limited physical abilities of the worms and basically integrates their bodies into the musical circuitry itself. It remains unclear if the worms are perceiving the low-voltage signals though their bodies and are capable of sensing any musical result at all.

Many of the musical examples we have found use a video tracking system to observe various animals and create sounds based on the overall movements of these animals. The most common species used in these systems are fish in an aquarium. Since the mid-2000s, this idea has been explored in different fields with various fish species. For example, The Accessible Aquarium is a long-time project of the Georgia Institute of Technology in Atlanta that is based on the field of informal learning environments. It attempts to make aquaria, zoos, and science centers more accessible for visitors through interaction and sonification, and thus enhance the visitors' learning experience [25]. The Accessible Aquarium environment allows visitors to mimic the animals' movements by using tangible objects to tell when a new fish enters the viewing range, what kind of fish it is, and in what direction it's moving; or add sounds or melodies to a specific aquarium fish. Sonifications corresponding to the visitors' movements can be paired with real-time animal-based sonifications produced by the existing system to generate a musical composition of the visitors and the fish [26].

Other fish-based projects such as FuXi [24], Submersed Songs [27], Quintetto ([28], Figure 2), Musica sull'Acqua [29], and Sonification of Fish Movement [30] take a more artistic approach. Here, fish are employed as musical instruments and interfaces for sound installations or musical performances. Even though all of the projects mentioned above use a video tracking system, they differ from each other in the way in which sound is mapped to the fishes' movement and what kind of sound was generated. Although it has been shown that some fish species such as carp can discriminate between different styles of music [34], and gurnard also have audio communication skills [35], these particular abilities have not been investigated within the fish-based projects found in this field.

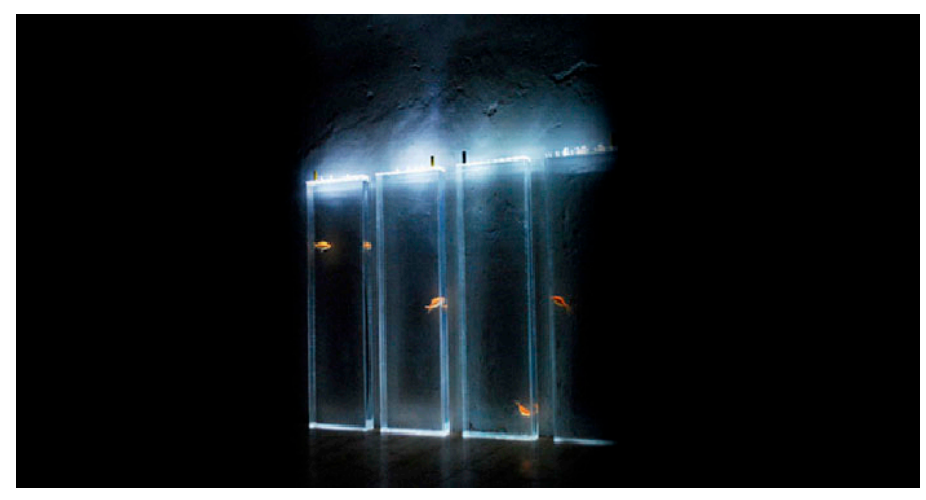

Figure 2. Fish-based instrument Quintetto by Quiet ensemble 2009 [19]. 


\subsection{Animals as Unconscious Performers}

This section deals with projects that involve animals directly touching or triggering the interfaces, instruments, or sensors, and also involves species that have a developed hearing capability. Nevertheless, these species lack a general cognitive understanding of the causality of their actions in relation to the musical results, and are therefore unconscious musical performers. The Intelligent MIDI Sequencing with Hamster Control project by Levy Lorenzo was a musical instrument that generated sounds based on the movements of six hamsters. Each hamster was placed inside a narrow single track where they could only move in a lateral direction. Based on the effective range of a distance sensor and the typical length of a hamster, Lorenzo decided to build 36-inch tracks. This allowed the hamsters to walk, sit up, and turn around while still remaining within sight of the distance sensor [36]. The sounds generated depended on the distance of the hamster from the sensor. The hamsters had no free choice to interact with the instrument, and they had only limited space to move within the instrument tracks. It is unclear how long the hamsters had to stay in the instrument.

Robert Wechsler adopted a different approach in his Harness project [31]. He combined a mouse cage, including a mouse wheel, with a music box situated outside of the cage. When the mouse exercised on the wheel, it powered the music box, and thus produced the sounds stored within it. Based on our work with grey parrots [37], we assume that it is a good approach for utilizing a well-established device for pet environments. However, positioning the music box outside of the cage and therefore shielding it from direct audio feedback in the cage seems disadvantageous, since it also isolates the mouse from the musical result.

A well-known art project is from here to ear ([32], Figure 3) by Céleste Boursier-Mougenot. Since 1999, he has been developing musical environments and installations for finches in public exhibitions. The installations combine a set of traditional musical instruments-mainly electric guitars and drums - that serve as a resting place for the finches and produce sounds upon contact. The public is invited to enter the installation space and mingle with the finches, whose movements generate a live musical piece. Each installation can be considered as a unique piece that is living and ephemeral; it is determined by the given variables of the situation and linked to the circumstances of the given moment [32]. Influenced by the audience, the finches generate a random sound collage that allows for minimal compositional procedures and choreographies defined by spatial arrangements. This project is currently one of the most established installations in the field of animal-human sound installation. Since it has been shown that finches have musical abilities [14,16], it would be interesting to provide them with musical instruments that are adapted to the physical skills of the finches.

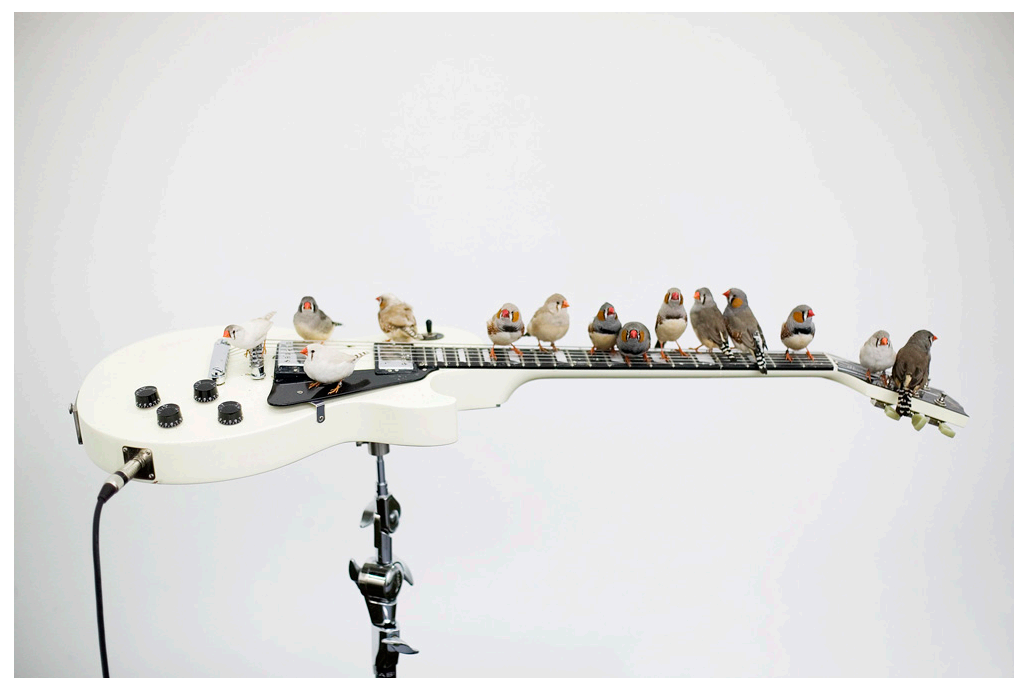

Figure 3. From here to ear by Celeste Boursier-Mougenot [32]. 


\subsection{Animals as Trained Musicians}

In this section, we shall look at projects in which animals become active music performers. There are numerous entertaining videos circulating virally around the Internet showing animals playing musical instruments. On video-sharing websites, there are numerous videos of dogs [38] and cats [39] playing the piano, trained seals playing toy wind instruments [40], and hens playing toy instruments [41].

In 2014, the zookeepers of the Smithsonian's National Zoo in Washington D.C. provided their zoo animals with some musical instruments [42]. For example, they equipped their otters with a keyboard and the orangutans with xylophones. The zoo's intention was to enhance the well-being of the captive animals, keep them active, and enrich their environment. They used traditional instruments designed for humans such as keyboards, xylophones, and harmonicas, which obviously was a disadvantage to some animals with different physiologies. Thus, it seems that the zookeepers did not select the instruments based on the skills of the different animal species.

Elephants are another species that have been given musical instruments to enrich their lives in captivity. An early attempt in this regard was made by the Thai Elephant Conversation Center with its Thai Elephant Orchestra (Figure 4). With the intention of creating music for humans, they designed and built massive musical instruments adapted to the physical abilities of the elephants. In 1997, the orchestra made its first recording with five elephants, and subsequently released an audio CD in 2001. From the very beginning, it was clear that elephants could, through endless repetition, be taught to play complex patterns [43]. However, the creators decided that making music should also be fun for the elephants. Thus, the only commands given to the elephants were to start, stop, and occasionally the number of times to strike an instrument [43].

The instruments that were used in the orchestra were mainly percussion instruments that the elephants could play with their trunks. The percussion instruments ranged from slit drums, marimba-like instruments, and gongs to thunder sheets, bells, and xylophones. Other instruments included single-string instruments, harmonicas, and wind instruments. The designs of the instruments were adapted to the elephant's anatomy and skills, and to the Thai cultural environment in which the animals lived. The elephants often heard Thai music; therefore, the instruments were adapted to sound similar to Thai instruments [43]. It has also been observed that elephants can play a steady beat $[44,45]$. During the course of the project, it was shown that they could make music together with other elephants and humans [44]. The combination of good instrument design and the elephants' musical skills makes this project a promising approach. That the project was founded to raise money for the Thai Elephant Conversation Center and thus became a tourist attraction may have had a negative impact on the animals. For instance, the project focused on training elephants to play human-like music for a human audience. It would have been interesting to see what would have happened without any training, by just providing the elephants with musical instruments and seeing what kind of musical output they created without the need to entertain a crowd of visitors.

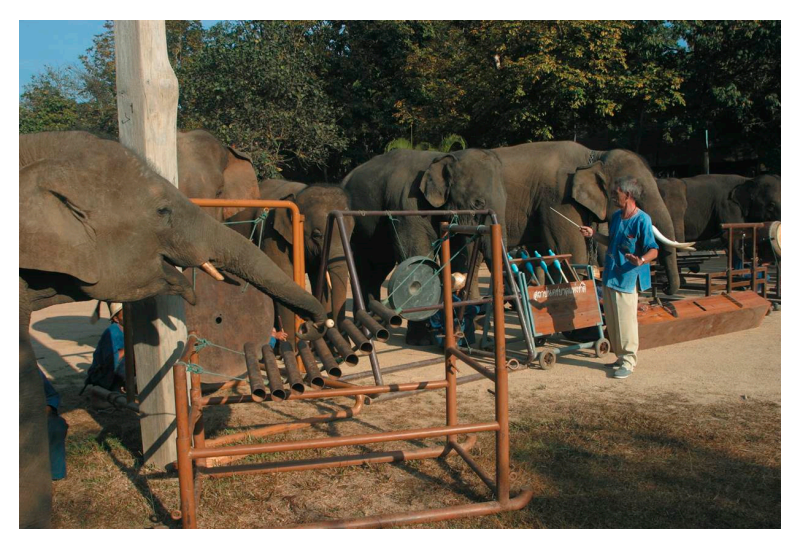

Figure 4. The Thai Elephant Orchestra [43]. 


\subsection{Animals as Voluntary Musicians}

In the context of ACI, Fiona French [6] is currently investigating the potential of technological enrichment for captive elephants. The design of the interactive toys for elephants also focuses on acoustic enrichment experiences. For example, one design concept was based on a harp-like instrument that the elephants could play with their trunks [46]. In collaboration with animal welfare experts and elephant keepers, French utilized sensors and switches for triggering sounds. The sounds were adapted to the elephants' preferences, and $60-70 \mathrm{~Hz}$ frequencies were used to arouse the interest of the participating elephant Valli [46]. A further relevant study in ACI was carried out with orangutans in zoos by Pons [7]. A sound-based interactive system was developed for auditory enrichment. Instead of providing orangutans with human music, the system allowed the animals to explore different types of sounds by manipulating tangible objects. The sound preferences of the orangutans were incorporated into the design process, thus making it animal-centered. In our opinion, the works of French and Pons could be seen as best practices in the context of $\mathrm{ACI}$, and both approaches could be used for the development of musical instruments and interfaces for other species as well.

metamusic is a project by the artist group alien productions (Martin Breindl, Norbert Math, and Andrea Sodomka) that was produced in cooperation with a group of African grey parrots. Since 2012, the artists have been working in close collaboration with zoologists, biologists, and animal keepers.

The initial idea behind the project was to develop interactive sound installations for animals held in captivity in zoological gardens. Much remains to be done to offer new challenges and diversions to the zoo inhabitants. metamusic aims to build electronic sound installations to be used by the animals themselves. Using a wide range of sensors and tools, the animals are able to explore and play with sounds and sonic moods. Based on the advice of their zoological collaborators, they have centered their attention on parrots, which have turned out to be the ideal animal species because of their nature. Although they are regarded as wild animals with complex social flocking behavior, each of the birds has been bred or at least raised by humans.

The metamusic project has shown that there is great potential for these kinds of open-sound environments and grey parrots. In collaboration with the grey parrots, the artists have been developing and modifying mechanical and electronic instruments and tools that can be played by the birds themselves. Fine-tuned sensors provide interactive modulation of the sounds. Nevertheless, the musical patterns and sonic structures generated by the parrots are not meant to sound aesthetically meaningful to human ears. The project also intend for the parrots communicate with each other by means of their own musical output created by their personalized instruments ([9], Figure 5).

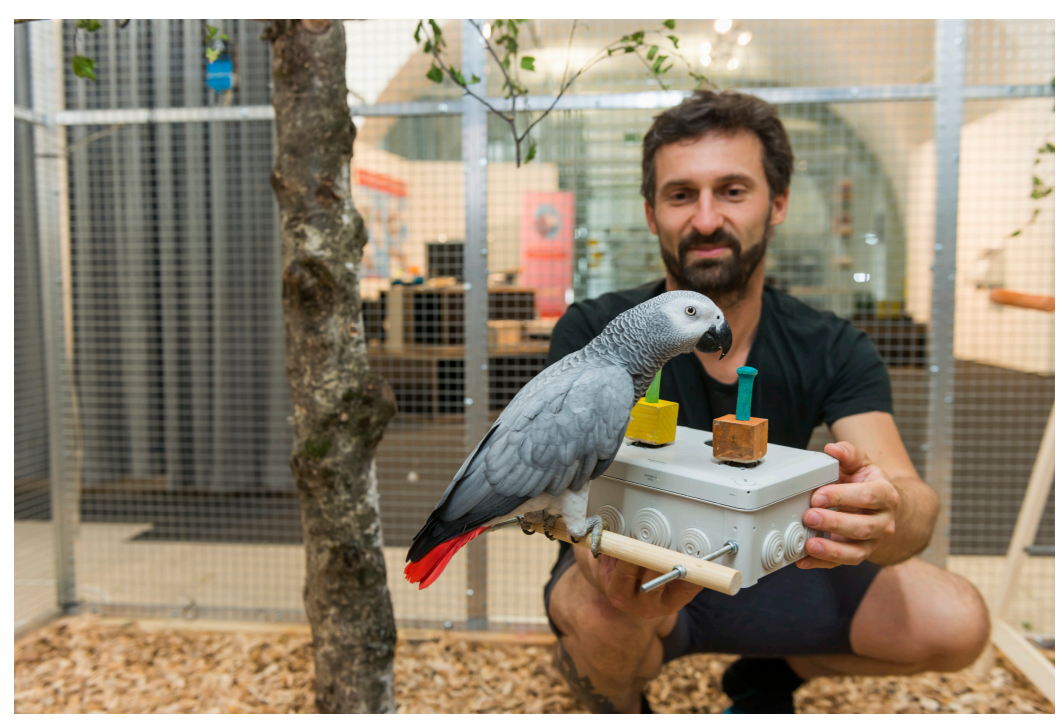

Figure 5. metamusic, joystick device [37]. 


\section{Animal-Centered Musical Interaction Design}

In general, all of the projects presented above have strengths and weaknesses in terms of their concepts and implementations. There are already promising approaches to improve the quality of life for animals in captivity with the use of music and sounds. In some of the projects, the selection of animal species seems arbitrary and not related to the animals' cognitive and physical skills. We have shown that some projects lack an animal-centered perspective, and many of the participating animals do not voluntarily intend to generate music by interacting with the provided interface or instrument. Additionally, many animals have been specifically trained or conditioned in order to perform predefined musical patterns.

Some of the projects also raise questions regarding the design of interfaces and musical instruments, which were not explicitly adapted to the abilities and needs of the participating animals. The use of traditional musical instruments designed for humans may not be appropriate, and reveals a lack of an animal-centered design approach, as proposed in Mancini's ACI manifesto [9]. In some cases, the animals had no choice between different musical instruments or interfaces. It is hard to imagine that more ambitious musical performances could be performed in these settings, and ethical principles are another consideration altogether.

Another question that needs to be addressed is the meaning of sound and music to the animals. Although there are approaches to adapt the frequencies of the sounds $[6,37,46]$ or the music to the personal preferences of the animals [1,7], there is no evidence that any species appreciated the acoustic stimuli. A number of studies in the field of biomusicology, for example [47-50], have found that animals prefer sounds and musical arrangements that are biologically relevant for them. This important point was not considered in the examples provided above, and it is therefore questionable if any of the approaches provided beneficial enrichment to the animals.

Our work is focused on finding a framework that would fulfill the challenging tasks of implementing an animal-centered design process, generating an artistic output, and above all, helping to stimulate discussion about enriching the quality of life of grey parrots in captivity. In the next section, we shall look at the key points involved in the implementation of musical interfaces for animals.

\subsection{Musical Capabilities}

The selection of an appropriate animal species for participation in the interaction process with musical instruments and interfaces is of essential importance. Based on expertise gathered from animal cognition [14], we have identified several animal species that have a particularly high degree of musicality, such as spontaneous entrainment, in comparison to others. Hoeschele's list of species with vocal learning and entrainment abilities also shows those animal species that have been tested and shown to have musical skills.

As Figure 6 shows, vocal learning ability is generally a good indicator that the species has strong auditory skills. Entrainment in animals is unusual, and involves the ability to align their movements to a musical beat. This ability has been found in grey parrots, cockatoos, and elephants, and has thus disproved the claim that entrainment to music is unique to humans $[17,18]$. These animals are able to move synchronously to music. Therefore, it is reasonable to assume that these animals can also maintain a rhythm with a steady tempo, as the active music performers of the Thai Elephant Orchestra have demonstrated. The animals on the list have the best prerequisites for playing an active role in projects that involve musical instruments. The questions of whether these talented animals appreciate music and whether they like making music or not require further study. Finally, whether the music created by animals pleases people is secondary to an animal-centered approach, and as such, animal music need not sound like music to human ears.

A further approach would be to select an animal species that is close to humans such as chimpanzees. It seems likely that they would share some human cognitive abilities [14], and thus would be interesting for further research. For example, orangutans, another related species, have shown interest in sound objects for individual auditory enrichment [7]. The Toronto Zoo 
conducted a study to determine the music preference of orangutans by using a participant-controlled, dichotomous-choice design. The orangutans were trained to indicate their music preference via touchscreen [1]. Furthermore, the orangutans of the Smithsonian's National Zoo in Washington D.C. were equipped with xylophones, and it was reported that they showed interest in playing them [42].

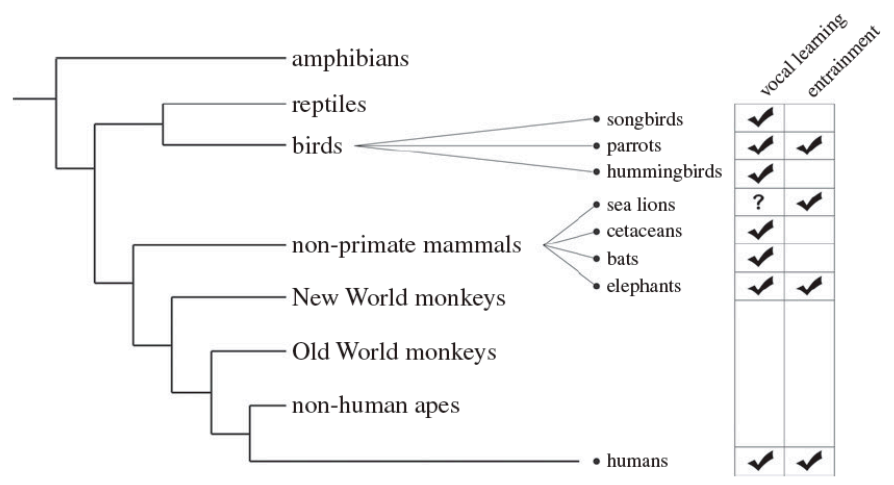

Figure 6. Vocal learning and entrainment in animals according to Hoeschele [14].

\subsection{Physical and Cognitive Abilities}

Another crucial question concerns the development of an appropriate animal-centered design approach, which concentrates on the specific physical and cognitive capabilities of each species, as well as its specific needs. The main problem here is to gather and understand the animal feedback. This requires different techniques [2], such as a review of the relevant literature on the animal species, the observation of the animals in their living environment, and the development of testing prototypes [46]. The design process of such testing prototypes should also be based on the results of cognitive science and animal behavior, as well as an analysis of the physical capabilities of the animal participants. The sounds and music that are used need to take the individual differences of the animals into account. Our work with grey parrots [37] and French's work with elephants [46] show that it is also necessary to adjust the pitches of the audio frequencies to make them better perceptible for the animal species.

\subsection{Engagement versus Training}

With regard to the various projects presented above, there are several different approaches to motivating the animal species that are involved in the installations. The scope ranges from imprinting behaviors, intense training, and rewarding through food to setups in which the animals were free to interact with the instruments and were only rewarded and motivated though the sounds generated by their actions. We believe that a setup that relies on the animals' satisfaction to motivate them to make sounds with the musical instruments is suited for animal species such as elephants and grey parrots, which have been proven to have some form of musical skills. An engaging, playful sonic system may provide a self-training environment to improve the animals' musical skills. The animals' intrinsic motivation could be one of the keys to successfully implementing this kind of technology to improve the well-being of animals in captivity [51,52]. For example, French uses such an approach in her work with elephants $[6,46]$. The elephants are already integrated into the design process by voluntarily testing different sensors for their user interfaces. In contrast, there are elephants that are trained to play musical instruments [43] or draw pictures under the guidance of trainers. A study of four captive Asian elephants at the Melbourne Zoo, Australia, examined painting by elephants in zoos [53], which is believed to be a form of enrichment. However, the results indicated that the elephants gained little enrichment from the activity of painting. 


\section{Future Work}

Our further research aims to show that grey parrots in captivity can generate unique artistic outcomes with musical instruments and interfaces in playful environments, in which grey parrots can freely choose which instrument they want to play or interact with, thereby adopting an active role as a performer. We believe there is a chance to foster relationships between grey parrots and humans by opening new creative communication processes based on sound and music. The project could expand the horizon of ACI research by developing musical instruments and interfaces for animals, and could also provide further contributions to design concepts in other disciplines such as $\mathrm{HCI}$ or animal behavior. Therefore, we conducted a series of experiments with a group of grey parrots at the ARGE Papageienschutz animal shelter [37]. There, we tested the auditory skills and preferences of the grey parrots as a group, while also identifying any individual characteristics. These tests were carried out in cooperation with zoologists, and respected the ethical principles of the ACI manifesto [21]. However, a suitable methodology that allows the grey parrots to participate in the design process itself has yet to be found. Our design intended to avoid any conditioning of the animals, and instead supported their inherent capabilities and needs. The individuals from our group of grey parrots generally preferred a loudness and pitch matching their own communication habits, as well as generally faster rhythms [37].

Based on the musical skills and preferences of our group of grey parrots, we subsequently moved on to design a series of analog musical instruments and computer-controlled interfaces that adapt to these capabilities. We also incorporated our observations of the grey parrots' behaviors toward and interactions with our experimental musical interfaces. We observed a general curiosity toward any new artifact that we added to the environment, leading to an overall exploration and a tendency toward trying to disassemble the whole artifact. While we initially tried to work around these behaviors, we eventually decided to incorporate these interactions into the fundamental interaction design of our musical artifacts. We are currently designing new musical instruments that are based on traditional design metaphors such as string and percussion instruments, or more contemporary designs such as digital turntables. Finally, we are also planning to incorporate the animals' highly developed vocal capabilities into an acoustic feedback design. All of these designs also consider the particular physical interaction patterns of grey parrots, which are mostly performed with the parrot beak. So far, we have implemented two instruments, and according to our observations, the grey parrots playfully interacted with them. One of them, the disc jockey (DJ) instrument, is based on a foraging wheel for parrot enrichment, in which the birds have to spin a wheel to collect their treats. When a grey parrot spins the wheel of the DJ instrument (Figure 7), the parrot will not be rewarded with food but with sound. Since the parrots are already familiar with this form of interaction, they should be able to learn quickly how to operate the device to get their reward. In further experiments with the DJ turntable instrument, we want to find out in more detail whether different sounds are perceived as a reward or a positive experience by the grey parrots.

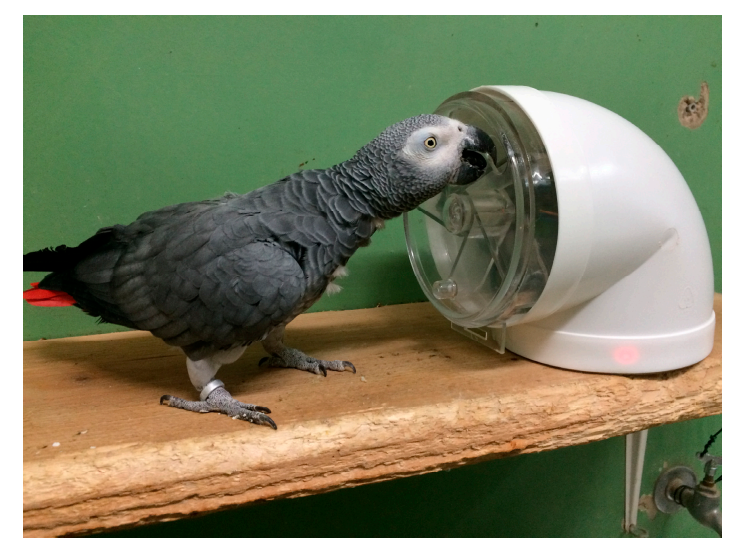

Figure 7. metamusic, disc jockey (DJ) device [7]. 
The second device is a collaborative instrument (Figure 8) in which a parrot plays "hand-in-hand" with another parrot or a person. It consists of a tube with a spring reverb installed inside that can be triggered from both sides by pulling on a rope. The tube instrument is intended to stimulate the birds' interest in interacting and making music together, since grey parrots usually live in long-term couple relationships. We are also focusing on designing further experimental musical instruments and carrying out different sonic experiments for use in art installations and performances. At the same time, we are giving careful consideration to whether the musical instruments and interfaces developed have the potential to improve the quality of life of grey parrots in captivity.

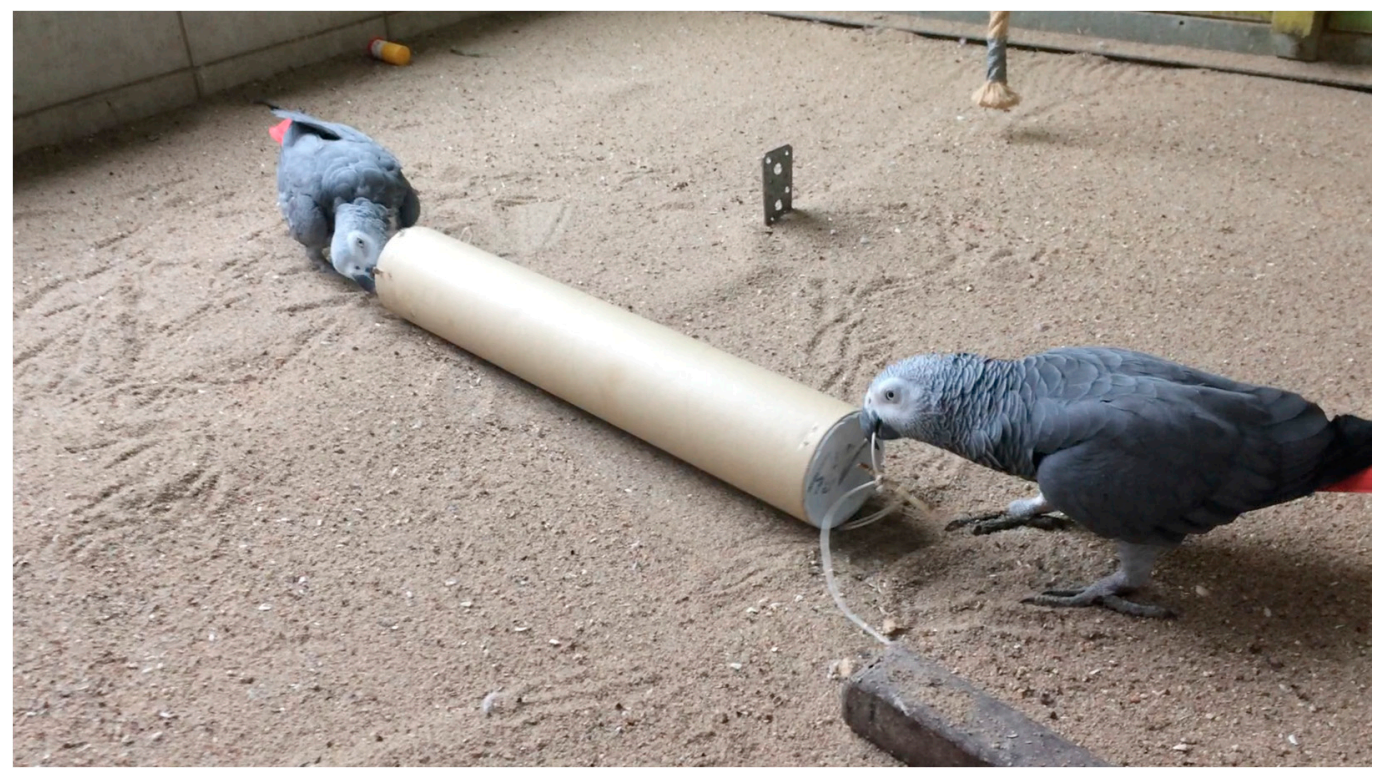

Figure 8. metamusic, tube device [8].

\section{Conclusions}

Our overview of recent musical instruments and interfaces that involve animals in the interaction and music-generation process is novel, and highlights the costs and benefits of projects of this kind. It provides insights into current technologies in this field and the musical talents of animals. Some of the participating animal species such as elephants and grey parrots have shown musical abilities and skills in musical performances. We have proposed a classification based on the role that the animals play as a collaborator in the musical environments and performances. Only the few projects presented above in Section 3.4. Animals as Voluntary Musicians seem to be promising technological and musical mediators between the animals themselves and between animals and humans. Thus, they present approaches to improve the quality of life of animals in captivity.

Based on our earlier work, we plan to continue with our practice-based research approach to develop new musical instruments and interfaces for grey parrots living in captivity. Ultimately, we hope to identify general cross-species design patterns for musical instruments from our research, which may even become relevant to human-centered design aspects.

Funding: This project is supported by the Austrian Science Fund FWF through the Programme for Arts-based Research (PEEK AR 349-G24).

Acknowledgments: We'd also like to thank our partners Martin Breindl, Andrea Sodomka and Norbert Math from alien productions as well as the animal keepers from ARGE Papageienschutz.

Conflicts of Interest: The authors declare no conflict of interest. 


\section{References}

1. Ritvo, S.; Allison, R. Challenges Related to Nonhuman Animal-Computer Interaction: Usability and 'Liking'. In Proceedings of the 2014 Workshops of Advances in Computer Entertainment Conference (ACE'14 Workshops), Funchal, Portugal, 11-14 November 2014.

2. Westerlaken, M.; Gualeni, S. Digitally Complemented Zoomorphism: A Theoretical Foundation for Human-Animal Interaction Design. In Proceedings of the 6th International Conference on Designing Pleasurable Products and Interfaces (DPPI'13), Newcastle, UK, 3-5 September 2013.

3. FitBark. Available online: https:/ /www.fitbark.com/ (accessed on 20 April 2018).

4. CleverPet. Available online: https://clever.pet/ (accessed on 20 April 2018).

5. PupPodSmartDogToys. Available online: https://puppod.com/ (accessed on 20 April 2018).

6. French, F.; Mancini, C.; Sharp, H. High tech cognitive and acoustic enrichment for captive elephants. J. Neurosci. Methods 2018, 300, 173-183. [CrossRef] [PubMed]

7. Pons, P.; Carter, M.; Jaen, J. Sound to your objects: A novel design approach to evaluate orangutans' interest in sound-based stimuli. In Proceedings of the 3rd International Conference on Animal-Computer Interaction, Milton Keynes, UK, 16-17 November 2016. [CrossRef]

8. Hermans, N.F.H.; Eggen, J.H. Beyond Barriers: Exploring Opportunities of Digital Technology to Encourage Personal Interaction between Captive Orangutans and Zoo Visitors, HCI Goes to Zoo. In Proceedings of the 2016 CHI Conference Extended Abstracts on Human Factors in Computing Systems, San Jose, CA, USA, 7-12 May 2016.

9. metamusic Project Web-Site. Available online: http:/ / metamusic.at/ (accessed on 20 April 2018).

10. Mingle, M.E.; Eppley, T.M.; Campbell, M.W.; Hall, K.; Horner, V.; de Waal, F.B.M. Chimpanzees Prefer African and Indian Music over Silence. J. Exp. Psychol. Anim. Learn. Cognit. 2014. [CrossRef] [PubMed]

11. Krohn, T.C.; Salling, B.; Hansen, A.K. How do rats respond to playing radio in the animal facility? Lab. Anim. 2011. [CrossRef] [PubMed]

12. Robbins, L.; Margulis, S.W. The Effects of Auditory Enrichment on Gorillas. Zoo Biol. 2014. [CrossRef] [PubMed]

13. Wells, D.H.; Irwin, R.M. Auditory stimulation as enrichment for zoo housed Asian elephants (Elephas maximus). Anim. Welf. 2008, 17, 335-340.

14. Hoeschele, M.; Merchant, H.; Kikuchi, Y.; Hattori, Y.; Cate, C. Searching for the origins of musicality across species. Philos. Trans. R. Soc. Lond. B Biol. Sci. 2015, 370. [CrossRef] [PubMed]

15. Bottoni, L.; Massa, R.; Lenti Boero, D. The grey parrot as musician: An experiment with the Temperate Scale. Ethol. Ecol. Evol. 2003, 15, 133-141. [CrossRef]

16. Ten Cate, C.; Spierings, M.; Hubert, J.; Honing, H. Can birds perceive rhythmic patterns? A review and experiments on a songbird and a parrot species. Front. Psychol. 2016, 7. [CrossRef] [PubMed]

17. Patel, A.; Iversen, J.; Bregman, M.; Schulz, I. Experimental Evidence for Synchronization to a Musical Beat in a Nonhuman Animal. Curr. Biol. 2009, 19, 827-830. [CrossRef] [PubMed]

18. Schachner, A.; Brady, T.; Pepperberg, I.; Hauser, M. Spontaneous motor entrainment to music in multiple vocal mimicking species. Curr. Biol. 2009, 19, 831-866. [CrossRef] [PubMed]

19. Porter, D.; Neuringer, A. Music discriminations by pigeons. J. Exp. Psychol. Anim. Behav. Process. 1984, 10, 138-148. [CrossRef]

20. Pepperberg, I.M. Cognitive and communicative abilities of Grey parrots. Appl. Anim. Behav. Sci. 2006, 100, 77-86. [CrossRef]

21. Mancini, C. Animal-Computer Interaction (ACI): A manifesto. Interactions 2011, 18, 69-73. [CrossRef]

22. Pig Organ. Available online: https:/ / commons.wikimedia.org/wiki/File:La_Piganino.jpg (accessed on 20 April 2018).

23. Chimpanzee Band: "Monkey Circus". Available online: https://www.youtube.com/watch?v=3zQ86n1OP_w (accessed on 20 April 2018).

24. Cordeiro, J. FuXi: A Fish-Driven Instrument for Real-Time Music Performance. In Proceedings of the 4th International Conference, EvoMUSART 2015, Copenhagen, Denmark, 8-10 April 2015.

25. Jeon, M.; Winton, R.J.; Yim, J.-B.; Bruce, C.M.; Walker, B.N. AquariumFugue: Interactive sonification for children and visually impaired audience in informal learning environments. In Proceedings of the 18th International Conference on Auditory Display (ICAD 2012), Atlanta, GA, USA, 18-21 June 2012. 
26. Jeon, M.; Winton, R.J.; Henry, A.G.; Oh, S.; Bruce, C.M.; Walker, B.N. Designing Interactive Sonification for Live Aquarium Exhibits. In Proceedings of the $2013 \mathrm{HCI}$ : International Conference on Human-Computer Interaction, Las Vegas, NV, USA, 21-26 July 2013; pp. 332-336.

27. Vivian, C. Submersed Songs. Available online: https://www.youtube.com/watch?v=uhTCf_311Eg (accessed on 20 April 2018).

28. Quiet Ensemble: Quintetto. Available online: http://www.quietensemble.com/quintetto.html (accessed on 20 April 2018).

29. Baldan, S.; Ludovico, L.; Mauro, D. Musica Sull'Acqua. In Proceedings of the 9th Sound and Music Computing Conference (SMC2012), Copenhagen, Denmark, 12-14 July 2012.

30. Mercer-Taylor, A.; Altosaar, J. Sonification of Fish Movement Using Pitch Mesh Pairs. In Proceedings of the 15th International Conference on New Interfaces for Musical Expression (NIME'15), Baton Rouge, LA, USA, 31 May-3 June 2015.

31. Wechsler, R. Harness. Available online: http:/ / robertwechsler.com/harness (accessed on 20 April 2018).

32. Boursier Mougenot, C. From Here to Ear. Available online: http://www.xippas.com/artists/celeste-boursiermougenot/ (accessed on 20 April 2018).

33. Ciat-Lonbarde, P. Din Datin Dudero. Available online: http://www.ciat-lonbarde.net/dindatindudero/ (accessed on 20 April 2018).

34. Chase Ava, R. Music discrimination by carp. Anim. Learn. Behav. 2001, 29, 336-353. [CrossRef]

35. Ladich, F. Acoustic Communication in Fishes: Sound Production, Hearing and the Effect of Noise. Master's Thesis, Verhaltensbiologie, Universität Wien, Vienna, Austria, 2012.

36. Levy Marcel Ingles Lorenzo. Intelligent MIDI Sequencing with Hamster Control; Cornell University: Ithaca, NY, USA, 2003.

37. Gupfinger, R.; Kaltenbrunner, M. Sonic Experiments with Grey Parrots: A Report on Testing the Auditory Skills and Musical Preferences of Grey Parrots in Captivity. In Proceedings of the 4th International Conference on Animal-Computer Interaction (ACI2017), Milton Keynes, UK, 21-23 November 2017.

38. Funny Dogs Playing Piano Compilation 2018. Available online: https://www.youtube.com/watch?v= OEcSKyVo950 (accessed on 20 April 2018).

39. Cat Playing Piano Like Beethoven. Available online: https://www.youtube.com/watch?v=ypJDXayM5FM\& $\mathrm{t}=21 \mathrm{~s}$ (accessed on 20 April 2018).

40. Super-Cute Baikal Seals Master Sax Playing \& Painting. Available online: https://www.youtube.com/ watch?v=ferKjZ5MQrA (accessed on 20 April 2018).

41. Flockstars: Chicken Band. Available online: https://www.youtube.com/watch?v=UBdEo9kyqT0 (accessed on 20 April 2018).

42. Smithsonian Magazine: Otters Play a Piano at the National Zoo. Available online: http://www. smithsonianmag.com/videos/category/science/otters-play-a-piano-at-the-national-zoo/ (accessed on 20 April 2018).

43. Thai Elephant Conservation Center: Homepage. Available online: http://www.thailandelephant.org/ (accessed on 20 April 2018).

44. Solder Dave: The Thai Elephant Orchestra. Available online: http:/ / mulatta.org/articles/DaveKinship\% 20with\%20Animals.pdf (accessed on 20 April 2018).

45. Solder, D. Eine Kleine Naughtmusik: How Nefarious Nonartists Cleverly Imitate Music. Leonardo Music J. 2002, 12, 53-58. [CrossRef]

46. French, F.; Mancini, C.; Sharp, H. Designing Interactive Toys for Elephants. In Proceedings of the 2015 Annual Symposium on Computer-Human Interaction in Play-CHI PLAY'15, London, UK, 5-7 October 2015; ACM Press: New York, NY, USA, 2015; pp. 523-528.

47. Snowdon, T.; Teie, D. Affective responses in tamarins elicited by species-specific music. Biol. Lett. 2010, 6, 30-32. [CrossRef] [PubMed]

48. Snowdon, T.; Teie, D.; Savage, M. Cats prefer species-appropriated music. Appl. Anim. Behav. Sci. 2015. [CrossRef]

49. Bowling, D.D.; Purves, D. A biological rationale for musical consonance. Proc. Natl. Acad. Sci. USA 2015, 112, 11155-11160. [CrossRef] [PubMed]

50. Chiandetti, C.; Avella, S.; Fongargo, E.; Cerri, F. Can clicker training facilitate conditioning in dogs? Appl. Anim. Behav. Sci. 2016. [CrossRef] 
51. Martin, A.J.; Collie, R.J.; Evans, P. Motivation and engagement in music: Theory, research, practice, and future directions. In The Arts, Motivation and Engagement: How the Arts Makes a Difference; Fleming, J., Gibson, R., Anderson, M., Eds.; Routledge: London, UK, 2016; pp. 169-185.

52. Baldassarre, G.; Stafford, T.; Mirolli, M.; Redgrave, P.; Ryan, R.M.; Barto, A. Intrinsic motivations and open-ended development in animals, humans, and robots: An overview. Front. Psychol. 2014, 5, 985. [CrossRef] [PubMed]

53. English, M.; Kaplan, G.; Rogers, L.J. Is painting by elephants in zoos as enriching as we are led to believe? PeerJ 2014, 2, e471. [CrossRef] [PubMed] 